\title{
Estimating fertilization success in marine benthic invertebrates: a case study with the tropical sea star Oreaster reticulatus
}

\author{
Anna Metaxas ${ }^{1, *}$, Robert E. Scheibling ${ }^{2}$, Craig M. Young ${ }^{3}$ \\ ${ }^{1}$ Department of Oceanography and ${ }^{2}$ Department of Biology, Dalhousie University, Halifax, Nova Scotia B3H 4J1, Canada \\ ${ }^{3}$ Department of Larval Ecology, Division of Marine Science, Harbor Branch Oceanographic Institution, \\ 5600 North US 1, Fort Pierce, Florida 34946, USA
}

\begin{abstract}
Several factors can influence fertilization success, and for marine broadcast spawners, the main constraint is rapid dilution of gametes. Because the measurement of fertilization success in the field is logistically difficult, theoretical models have been used as an alternative method of estimation. We tested the predictive ability of the existing models (time-averaged diffusion model in conjunction with a fertilization kinetics model) by making direct comparisons between empirical and corresponding predicted rates of fertilization in the tropical sea star Oreaster reticulatus. Using induced spawnings, we measured in situ fertilization in field experiments at 4 sites on sand bottoms and seagrass beds in the Bahamas. Rate of fertilization decreased exponentially with increasing distance downstream $(x)$ from a spawning male for all experimental runs at all sites, and when averaged across all sites, it ranged from $74 \%$ at $x=1 \mathrm{~m}$ to $31 \%$ at $x=32 \mathrm{~m}$. For each experimental run, we parameterized the 2 models by quantifying the flow field, and thus obtained predicted estimates of fertilization success. The shape of the fitted exponentially-decaying curves was similar between the observed and predicted data for sites on sand bottoms, but not in seagrass beds. There was a highly significant correlation between the observed and predicted data at each distance directly downstream for each run, but the predicted values were 1 to 10 orders of magnitude lower than the observed values for distances off the main axis of advection. We also used dye dilution runs to test the validity of the diffusion model and, in agreement with the observed values, the predicted concentrations of dye decreased as a power function of distance downstream from the point of release. Turbulent diffusivity was quantified in 2 ways: by measuring the standard deviation of dye concentration across-stream and vertically $\left(\sigma_{y}\right.$ and $\left.\sigma_{z}\right)$, and by calculating coefficients of diffusivity $\left(\alpha_{y}\right.$ and $\left.\alpha_{z}\right)$. Using $\alpha_{y}$ and $\alpha_{z}$ the values predicted with the model of diffusion were up to 24 orders of magnitude lower than the observed values at heights $>0.2 \mathrm{~m}$ above the bottom, but this inconsistency was alleviated when $\sigma_{y}$ and $\sigma_{z}$ were used. Thus, the combination of the 2 models currently used can predict fertilization rate reliably for a particular parameter space, which can be increased by quantifying turbulent diffusivity more accurately. These modified models can substitute field experiments to estimate fertilization success in species of marine benthic invertebrates that are fragile, such as $O$. reticulatus, or are relatively inaccessible, such as inhabitants of the deep sea.
\end{abstract}

KEY WORDS: Fertilization success · Field fertilization experiments · Time-averaged diffusion model · Fertilization kinetics model · Oreaster reticulatus $\cdot$ Fragile species

\section{INTRODUCTION}

Fertilization success (defined as the proportion of fertilized eggs) determines zygote production of a popula-

*E-mail: metaxas@is.dal.ca tion, which ultimately may have a pronounced effect on recruitment. Several factors can influence fertilization success, and they operate at the levels of gametes (e.g. sperm velocity, egg size), individuals (e.g. spawning behaviour, synchrony, reproductive output) and populations (e.g. density, distribution, size structure) 
(see Levitan 1995 for review). For marine broadcast spawners (animals that release sperm and eggs into the water column where fertilization occurs), the main constraint on fertilization success is rapid dilution of gametes. Thus, the potential effects of environmental factors, such as advective and turbulent flow, are particularly significant.

Determining fertilization success in the field is logistically difficult. Natural spawning events are witnessed rarely, and artificial induction of spawning can be unreliable. Fertilization during natural spawns has been measured in a few taxa, including asteroids (e.g. Babcock \& Mundy 1992), holothurians (e.g. Sewell \& Levitan 1992, Hamel \& Mercier 1996), gorgonian corals (e.g. Oliver \& Babcock 1992, Lasker et al. 1996, Coma \& Lasker 1997a,b), and fishes (e.g. Petersen 1991, Petersen et al. 1992). Field experiments of fertilization success based on induced spawnings have focussed on echinoderms (echinoids and asteroids), and have involved complicated experimental protocols, such as deployment of eggs in baskets (Levitan et al. 1992, Levitan \& Young 1995, Wahle \& Peckham 1999), arrays of females positioned downstream from spawning males (Babcock et al. 1994), and the use of drip bags for release of sperm (e.g. Babcock \& Keesing 1999).

An alternative to empirical measurements of fertilization success is prediction using theoretical modeling. Denny (1988) and Denny \& Shibata (1989) proposed using a time-averaged diffusion model, originally developed to estimate atmospheric dispersion (Csanady 1973), to predict concentration of gametes at a position downstream from a spawning individual. This diffusion model assumes that a plume is formed downstream from a point-source of continuous release of a tracer, such as gametes (Csanady 1973). The concentration of the tracer in the centre of the plume decreases with increasing distance downstream from the point of release, but the relative distribution of the concentration within the plume (i.e. the shape of the plume) remains constant (Okubo 1980). In the proposed model of gamete dispersion, advection is in the $x$-direction (along-stream) within a turbulent benthic boundary layer, and diffusion occurs in the $y$ (across-stream) and $z$ - (vertical) directions.

A model of fertilization kinetics can be used in conjunction with the model of diffusion to obtain an estimate of rate of fertilization at a position downstream of a spawning male (Vogel et al. 1982, Denny \& Shibata 1989). With this model, the proportion of eggs that will be fertilized at the specified position is calculated as the probability of sperm colliding with eggs, given the sperm concentration at that position as estimated from the diffusion model.

Denny \& Shibata (1989) categorized the 2 models as educational, 'modeling reality adequately in the sim- plest fashion possible', and they recommended that further studies should address their validity. Since then, 2 refinements have been made to the original models: (1) constraining vertical diffusion of gametes at shallow depths (Babcock et al. 1994); and (2) incorporating a block for polyspermy into the model of fertilization kinetics (Styan 1998). However, no direct test of the validity of the models has been published to date.

To test the validity of the models, meaningful comparisons of independently obtained empirical and predicted rates of fertilization are required. The models must be parameterized with measures of the in situ conditions, such as flow speed and diffusion, taken concomitantly with empirical measurements of fertilization. To parameterize the models, previous studies have used either a combination of literature-derived values and limited measures of in situ conditions (e.g. Levitan \& Young 1995, Babcock \& Keesing 1999, Babcock et al. 2000), or a subset of empirical data (e.g. Babcock et al. 1994). In this study, we tested the predictive ability of the models by making direct comparisons between empirical and corresponding predicted rates of fertilization in the tropical sea star Oreaster reticulatus. Using induced spawnings, we measured in situ fertilization in field experiments at 4 sites in the Bahamas. For each experimental run, we parameterized the 2 models by quantifying the flow field, and thus obtained predicted estimates of fertilization success. Also, we used studies of dye dilution to test the validity of the diffusion model by examining 2 independent measures of turbulent diffusivity.

Using Oreaster reticulatus as a model organism to test the predictive ability of the models of fertilization success has several advantages. At our study sites, this sea star occurs in shallow $(<5 \mathrm{~m})$ sand bottoms and sparse seagrass beds, which are habitats of relatively homogeneous bottom topography and low roughness and, thus, well-behaved near-bottom flows. O. reticulatus occurs at low densities ( 1 to 5 ind. $100 \mathrm{~m}^{-2}$ ) and small population sizes (200 to 4000 individuals) (Scheibling 1982a,b, Scheibling \& Metaxas 2001), factors which have a pronounced effect on fertilization success (Levitan 1991, Levitan et al. 1992, Levitan \& Young 1995). Thus, our study can provide insight into the reproductive biology of other species with similar characteristics of life history and population structure, such as deepsea taxa that are less accessible (e.g. Young et al. 1992). Lastly, we obtained estimates of fertilization success and, thus, potential of zygote production in a species which is becoming depleted because of anthropogenic influences. Although O. reticulatus used to be common throughout the Caribbean Sea, this species has been collected increasingly as a curio or ornament, and at present, populations exist only in areas with little human development or tourism (R.E.S. pers. obs.). 


\section{MATERIALS AND METHODS}

Field fertilization experiments. We measured in situ rates of fertilization in Oreaster reticulatus in each of 2 experiments conducted at each of 2 sites on sand bottoms (Tug and Barge Cay, TBC; Exuma Bank, EXB), and in seagrass (Thalassia testudinum) beds (Children's Bay Cay, CBC; and Norman's Pond Cay, NPC), near Lee Stocking Island in the Exuma Cays. These are shallow sites (TBC: 1.9 to $2.4 \mathrm{~m}$; EXB: 1.8 to $2 \mathrm{~m}$; CBC: 1.9 to $2.6 \mathrm{~m}$; NPC: 2.8 to $2.9 \mathrm{~m}$ ) on the Great Bahama Bank and all experience similar flow regimes (see 'Results'). The sites on sand bottoms (including Pudding Point, see following subsection) were on offshore banks bounded by sparse seagrass and shallow sand bars. NPC was bounded by the shore and dense seagrass and coral patches, whereas CBC was bounded by a tidal channel and a sand bar.

Experiments were conducted from 27 August to 5 September 1997 during the peak of the annual reproductive cycle of Oreaster reticulatus. Image-analysis of histological preparations of gonads, for 10 to 15 individuals from TBC, CBC, and NPC in August 1996 and 1997, showed that all sea stars were either ripe or recently spawned (Stages 4 or 5, Yoshida 1952, Young et al. 1992). In 1996, 75 and $25 \%$ of females and 100 and $80 \%$ of males at TBC and $\mathrm{CBC}$, respectively, were in Stage 4. In 1997 , $63 \%$ of females and $75 \%$ of males at TBC, and all individuals at NPC were in Stage 4. In both years, the remaining individuals were in Stage 5. Several spawning pairs of sea stars were used in each experiment, and for each pair, the female was placed at varying distances directly downstream and across stream from the male. A set of distances was selected for each experiment based on estimated distances to nearest neighbour in these populations, which at the peak of the reproductive cycle ranged from 2.8 to $8.3 \mathrm{~m}$ (Scheibling \& Metaxas 2001). It should be noted that distances to the nearest downstream mate were much greater, and approximately 4 times those to the nearest neighbour (Scheibling 2001). These positions were repeatedly sampled in sequence from the farthest to the nearest distance to the male (to minimize contamination) until there were no more available spawning pairs (Table 1). This procedure resulted in using $>1$ distance for each spawning pair, and $>1$ spawning pair at each distance. For the analyses, rate of fertilization at each distance was averaged across all spawning pairs. In some experiments, we included distances upstream from the spawning male to obtain an estimate of fertilization through procedural contamination or by naturally occurring sperm (Table 1).

Individuals were induced to spawn by injecting them with 8 to $10 \mathrm{ml} 10^{-4} \mathrm{M} 1$-methyladenine. When a pair of vigorously spawning sea stars became available, a diver carried the male to a predetermined position and monitored the rate of sperm release. With the male in position, the direction of downstream advection of the sperm plume (labelled with fluorescein dye released immediately above the male) was marked with a measuring tape placed on the bottom. Because experiments lasted $45 \mathrm{~min}$ to $2 \mathrm{~h}$, we released dye intermittently during the experiment and adjusted the marked direction, if necessary, to accommodate tidal changes. A second diver placed the female at a predetermined position downstream from the spawning male, which was relative to the marked direction of advection. After the sperm plume reached the female (as indicated by the dye cloud), the diver collected eggs for $60 \mathrm{~s}$ by holding a $63 \mu \mathrm{m}$ net (i.d. $0.133 \mathrm{~m}$, length $0.5 \mathrm{~m}$, including $0.13 \mathrm{~m}$ long cod end) $\sim 10 \mathrm{~cm}$ behind the female and $\sim 15 \mathrm{~cm}$ above the bottom (the average height of egg

Table 1. Oreaster reticulatus. Number of pairs used at each along-stream $(x)$ and across-stream $(y)$ distance from the male (positioned at $x=0, y=0$ ) in each experimental run of in situ fertilization near Lee Stocking Island, Exuma Cays, Bahamas. TBC: Tug and Barge Cay; EXB: Exuma Bank; CBC: Children's Bay Cay; NPC: Norman's Pond Cay

\begin{tabular}{|c|c|c|c|c|c|c|c|c|c|}
\hline \multicolumn{2}{|c|}{$\begin{array}{l}\text { Coordinates } \\
x(\mathrm{~m}) y(\mathrm{~m})\end{array}$} & \multicolumn{8}{|c|}{ Experimental run } \\
\hline-4 & 0 & 2 & & 1 & & & & & \\
\hline-2 & 0 & 2 & 2 & & & 1 & & 1 & \\
\hline 1 & 0 & & & & & 2 & 2 & & \\
\hline 2 & 0 & 3 & 3 & & & 2 & 2 & 2 & \\
\hline 4 & -1 & & & & 2 & & & & \\
\hline 4 & 0 & 3 & 4 & 2 & 3 & 3 & 2 & 4 & \\
\hline 4 & 1 & & & & 1 & & & & \\
\hline 8 & -3 & & & & 1 & & & & \\
\hline 8 & -2 & & & & 1 & & & & \\
\hline 8 & -1 & & & & 2 & & & & 2 \\
\hline 8 & 0 & 2 & 4 & 2 & 2 & 2 & 2 & 5 & 1 \\
\hline 8 & 1 & & & & 1 & & & & \\
\hline 16 & -5 & & & & 1 & & & & \\
\hline 16 & -4 & & & & 1 & & & & \\
\hline 16 & -3 & & & & 1 & & & & 2 \\
\hline 16 & -2 & & & & 1 & & & & 1 \\
\hline 16 & -1 & & & & 1 & & & & 1 \\
\hline 16 & 0 & & 3 & 5 & & 2 & 1 & 5 & 1 \\
\hline 16 & 1 & & & & & & & & 1 \\
\hline 16 & 2 & & & & & & & & 1 \\
\hline 16 & 3 & & & & & & & & 1 \\
\hline 24 & 0 & & & 4 & & & & 6 & \\
\hline 32 & 0 & & & 1 & & & & 6 & \\
\hline
\end{tabular}


release). At the end of the collection period, a third diver transported the net to a small boat where the contents of the cod end $(\sim 150 \mathrm{ml})$ were poured into sample containers. We did not concentrate the sample through a sieve to avoid damaging the eggs. The net was subsequently submerged in fresh water to kill any residual gametes.

The samples were transported to shore and fixed by adding a few drops of $10 \%$ formalin 2 to $3 \mathrm{~h}$ after collection. Rate of fertilization was determined as the proportion of collected eggs that were fertilized, as indicated by cell division. A minimum of 100 eggs was scored under a compound microscope. By using a $63 \mu \mathrm{m}$ mesh for collecting fertilized eggs, we assumed that the maximum sperm-egg contact time was less than the collection period, because the sperm (head length $=3 \mu \mathrm{m}$, tail length $=16 \mu \mathrm{m}$ ) would be advected through the net. We examined live subsamples for active or inactive sperm on 2 occasions (TBC, Expt 2: 3 samples from $2 \mathrm{~m}$ downstream; CBC, Expt 1: 1 sample from $1 \mathrm{~m}$ and 1 sample from $2 \mathrm{~m}$ downstream), and did not observe any.

For each site, we fitted exponential curves to the relationship between the observed proportion of eggs fertilized and distance downstream from a spawning male using nonlinear regression. Between paired combinations of sites, we compared the slopes and elevations of the regressions on the linear data after $\ln (x)$ transformation, using $t$-tests (Zar 1999).

To quantify the flow regime, we obtained flow profiles immediately before each fertilization experiment. We estimated flow speed at $0.10,0.25,0.50$ and $0.75 \mathrm{~m}$ above the bottom (mab), by timing (within $0.1 \mathrm{~s}$ ) the downstream displacement of a small puff of fluorescein dye over $1 \mathrm{~m}$. For each profile, we selected the freestream velocity $(u)$ as the maximum flow speed recorded either at 0.5 or 0.75 mab. We calculated the frictional velocity $\left(u_{*}\right)$ as:

$$
u_{*}=\kappa \frac{u_{2}-u_{1}}{\ln z_{2}-\ln z_{1}}
$$

where $\kappa$ is von Karman's constant (equal to 0.41), and $u_{1}$ and $u_{2}$ are the flow speeds at $z_{1}(=0.1 \mathrm{mab})$ and $z_{2}$ $(=0.25 \mathrm{mab})$, respectively. We fitted a logarithmic curve to each flow profile to ensure that the assumption of the shape of the profile required for the calculations was met.

Dye diffusion experiments. We also obtained empirical measures of diffusion of a dye (a passive tracer that is assumed to behave like released sperm) in the adult habitats of Oreaster reticulatus to further test the validity of the diffusion model. We measured dilution of the fluorescein dye at 2 sites on sand bottoms (TBC and Pudding Point, PPT) and at 1 site in a seagrass bed (CBC), from 18 to 23 June 1996. At each site, we mea- sured diffusion on several dates to incorporate a range of tidal states and wave conditions.

We measured the dilution of a dye plume by releasing fluorescein of a known concentration at a constant rate $\left(\sim 1 \mathrm{ml} \mathrm{s}^{-1}\right)$ from a fixed point at $0.1 \mathrm{mab}$, selected as the approximate height of a spawning Oreaster reticulatus. We collected seawater samples in the dye plume with hypodermic syringes $(60 \mathrm{ml})$ at 10 distances downstream from the point of release $(x=0.25$, $0.5,1,1.5,2,2.5,3,3.5,4$ and $5 \mathrm{~m}$ ), and 3 heights above the bottom $(z=0.1 \mathrm{~m}$ at $x=0.25$ and $0.5 \mathrm{~m} ; z=0.2 \mathrm{~m}$ at $x=1,1.5,2,2.5 \mathrm{~m}$; and $z=0.5 \mathrm{~m}$ at $x=3,3.5,4$ and $5 \mathrm{~m})$. Samples at each distance were collected from separate plumes. Dye concentration in the water samples was estimated spectrophotometrically at a wavelength of $460 \mathrm{~nm}$. Background fluorescence was below detection, and thus negligible relative to measured concentrations.

The diffusion coefficients $\sigma_{y}$ and $\sigma_{z}$ correspond to the standard deviation in the concentration of particles across the plume, in the $y$ and $z$ directions, respectively. The empirically measured width and height of a tracer plume released continuously from a fixed source is assumed to equal roughly $4 \sigma_{y}$ and $4 \sigma_{z \prime}$ respectively (Csanady 1973, Okubo 1980). To obtain in situ measures of horizontal and vertical diffusion, we estimated visually the width and height of plumes of dye using poles marked at $0.5 \mathrm{~m}$ intervals that were either driven into the sediment (for height measurements) or laid on the bottom (for width measurements), at $0.5,1,2$ and $4 \mathrm{~m}$ downstream from the point of release. An additional measure was taken at $3 \mathrm{~m}$ downstream for PPT because of the shallow depth at this site (1 to $1.3 \mathrm{~m}$ ). Three replicate measures were taken at each distance, and each was measured on a separate plume. These measures were then averaged to provide an average height and width for each distance. In all but 2 cases, the coefficient of variation of the 3 measures was 0 to $34 \%$. A flow profile was measured, as described in the preceding subsection, before and after each experimental run of dye dilution and diffusion.

Parameterization and validation of the models. We tested the predictive ability of the diffusion model and the model of fertilization kinetics by directly comparing empirical rates of fertilization (measured in the experiments) with corresponding predicted rates. For each run of the in situ fertilization experiments, we parameterized the 2 models by quantifying the flow field, and thus obtained independently predicted estimates of fertilization success.

For each experimental run, we calculated sperm concentration at each experimental distance using the model of gamete diffusion. This model estimates the concentration of gametes at a position (with $x, y$ and $z$ 
coordinates) downstream from a spawning individual placed at the origin $(x=0, y=0, z=0)$ as:

$G(x, y, z)=$
$\frac{Q u}{2 \pi \alpha_{y} \alpha_{z} u_{*}^{2} x^{2}} \cdot \mathrm{e}^{-\frac{y^{2} u^{2}}{2 \alpha_{y}^{2} u_{*}^{2} x^{2}}} \cdot\left(\mathrm{e}^{\frac{-(z+h)^{2} u^{2}}{2 \alpha_{z}^{2} u_{*}^{2} x^{2}}}+\mathrm{e}^{\frac{-(z-h)^{2} u^{2}}{2 \alpha_{z}^{2} u_{*}^{2} x^{2}}}+\mathrm{e}^{\frac{-(-2 D-z-h)^{2} u^{2}}{2 \alpha_{z}^{2} u_{*}^{2} x^{2}}}\right)$

where $Q$ is the rate of gamete release, $u$ is the freestream velocity, $\alpha_{y}$ and $\alpha_{z}$ are the coefficients of diffusivity in the $y$ and $z$ directions, respectively, $u_{*}$ is the frictional velocity, $h$ is the height of gamete release, and $D$ is the depth of the water column. We then estimated the proportion of eggs that will be fertilized at each experimental distance (with $x, y$ and $z$ coordinates) using:

$$
F(x, y, z)=1-\mathrm{e}^{-\phi \tau u_{*} G}
$$

where $\phi$ is the fertilizable cross-sectional area of the egg, $\tau$ is the sperm-egg contact time and $G$ is the sperm concentration at $x, y, z$ as estimated by Eq. (2).

The models were parameterized using measures collected in the laboratory and in the field. We measured $Q$ in the laboratory in September 1996 and 1997. Sea stars were collected from TBC, CBC and NPC and placed individually in $78 \mathrm{l}$ aquaria in the laboratory containing 10 $\mu \mathrm{m}$-filtered seawater. We induced spawning by injecting 8 to $10 \mathrm{ml} 10^{-4} \mathrm{M} 1$-methyladenine, and recorded time of initiation and termination of spawning as well as spawning intensity throughout this period. At the end of spawning, the sea star was removed from the aquarium after washing any residual gametes off its body. We stirred vigorously the water in the aquarium to homogenize gamete concentration, and removed subsamples (2 and 4 for counts of sperm and eggs, respectively). Gametes were counted with a microscope, using a hemocytometer for sperm and a Sedgewick-Rafter counting slide for eggs. We estimated the number of gametes released over the entire spawning period by multiplying the concentration (no. $\mathrm{l}^{-1}$ ) by the total volume of water in the aquarium. To obtain $Q$ (gametes $\left.\mathrm{s}^{-1}\right)$, we divided the

Table 2. Oreaster reticulatus. Rates of gamete release $(Q$, gametes $\mathrm{s}^{-1}$ ) from 3 populations near Lee Stocking Island, Exuma Cays, Bahamas, measured in the laboratory in September 1996 and 1997. Site abbreviations as in legend to Table 1

\begin{tabular}{|c|c|c|c|c|}
\hline \multirow[t]{2}{*}{ Site } & \multicolumn{2}{|c|}{ Sperm release rate } & \multicolumn{2}{|c|}{ Egg release rate } \\
\hline & Mean (n) & SE & Mean (n) & $\mathrm{SE}$ \\
\hline TBC & $8.37 \times 10^{6}$ & $3.11 \times 10^{6}$ & $607 \quad(9)$ & 195 \\
\hline $\mathrm{CBC}$ & $2.90 \times 10^{7}$ & $1.59 \times 10^{7}$ & $446 \quad(8)$ & 148 \\
\hline NPC & $1.27 \times 10^{8}$ & $2.49 \times 10^{7}$ & 690 & 269 \\
\hline Sand & $8.37 \times 10^{6}$ & $3.11 \times 10^{6}$ & $607 \quad(9)$ & 195 \\
\hline Seagrass & $6.15 \times 10^{7}$ & $1.63 \times 10^{7}$ & 527 (16) & 121 \\
\hline
\end{tabular}

total number of gametes by the length of the spawning period (Table 2). Release rates of sperm and eggs did not vary significantly between populations on sand bottoms and seagrass beds ( $t$-test on $\ln (x+1)$-transformed data: Table 2). Thus, we used a mean release rate (averaged over all sites) of $4.82 \times 10^{7}$ sperm s $^{-1}$ in the diffusion model for all experimental runs.

Free-stream velocity and frictional velocity were obtained for each experimental run as described above. For each $x$, we calculated the coefficient of diffusion in the $z$ direction using:

$$
\alpha_{z}=\sqrt{\frac{K_{z}}{u_{*}^{2} t}}
$$

where $K$ is the eddy diffusivity in the $z$ direction and $t$ is the time to travel from the point of release to $x$ at $u_{0.1}$ (Denny 1988, Denny \& Shibata 1989). In turn:

$$
K_{z}=\kappa u_{*} h
$$

where $\kappa$ is von Karman's constant, $u_{*}$ is frictional velocity, and $h$ is the height of gamete release (equal to $0.1 \mathrm{~m})$. For each $x$, we calculated the coefficient of diffusion in the $y$ direction as $\alpha_{y}=1.6 \alpha_{z}$ (Denny 1988, Denny \& Shibata 1989). For each run, we measured depth from a small boat with a $5 \mathrm{~m}$ pole marked at $0.1 \mathrm{~m}$ intervals.

For Eq. (3), we calculated $\phi$ as 3\% (Babcock et al. 1994) of total area. Mean egg diameter of Oreaster reticulatus was $224.4 \mu \mathrm{m}(\mathrm{SD}=5.97, \mathrm{n}=10)$, thus $\phi$ is $1.19 \times 10^{-9} \mathrm{~m}^{2}$. We set $\tau$ equal to $30 \mathrm{~s}$, or half the sampling period of eggs (60 s), because it represents the average period of exposure of the collected eggs to sperm.

We examined the predictive performance of the diffusion model when parameterized with 2 independent measures of turbulent diffusivity, using the dye diffusion studies. Firstly, for each experimental run of dye dilution, we estimated the concentration of dye using Eq. (2). The release rate of dye was $0.0014 \mathrm{~mol} \mathrm{~s}^{-1}$ for all runs except PPT, where it was $0.0021 \mathrm{~mol} \mathrm{~s}^{-1}$. All other parameters were estimated as for the fertilization experiments.

Additionally, we used the measurements of height and width of the plumes, and thus estimated $\sigma_{y}$ and $\sigma_{z \prime}$ to parameterize a different version of the model. Because in a turbulent boundary layer:

$$
\sigma_{y}=\alpha_{y}\left(\frac{u_{*}}{u}\right) x^{\beta} \text { and } \sigma_{z}=\alpha_{z}\left(\frac{u_{*}}{u}\right) x^{\beta}
$$

(where $\beta$ is a coefficient assumed to be equal to 1 ) (Denny \& Shibata 1989), Eq. (2) can be rewritten as:

$$
\begin{aligned}
& G(x, y, z)= \\
& \frac{Q}{2 \pi \sigma_{y} \sigma_{z} u} \cdot \mathrm{e}^{-\frac{y^{2}}{2 \sigma_{y}^{2}}} \cdot\left(\mathrm{e}^{\frac{-(z+h)^{2}}{2 \sigma_{z}^{2}}}+\mathrm{e}^{\frac{-(z-h)^{2}}{2 \sigma_{z}^{2}}}+\mathrm{e}^{\frac{-(-2 D-z-h)^{2}}{2 \sigma_{z}^{2}}}\right)
\end{aligned}
$$


For each $x$, we used the empirically measured width or height of the plume of the dye divided by 4 as $\sigma_{y}$ and $\sigma_{z}$ respectively (see preceding subsection).

For each fertilization and dye dilution experiment, we compared the predicted values at each distance with the corresponding values observed in the field using correlation analysis. For the fertilization experiments, we fitted exponential curves to the relationships between observed and predicted proportion of eggs fertilized and distance downstream from a spawning male, using nonlinear regression. For the dye diffusion experiments, we fitted logarithmic curves to the relationships between observed and predicted (estimated by using both $\alpha$ and $\sigma$ ) concentration of dye and distance downstream from the point of release. We com-
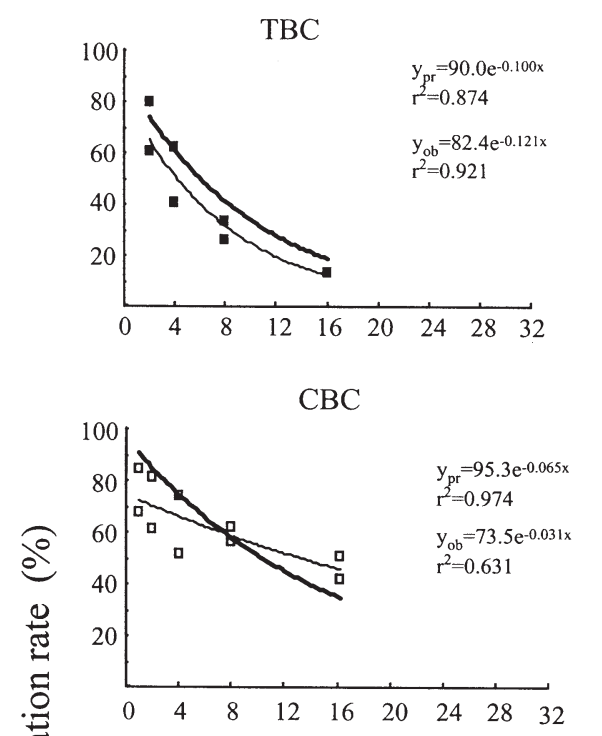

pared the slopes and elevations of the linear regressions fitted to the observed and predicted data after $\ln (x)$-transformation, using $t$-tests (Zar 1999).

\section{RESULTS}

\section{Field fertilization experiments}

Rate of fertilization in Oreaster reticulatus decreased exponentially with increasing distance downstream from a spawning male for all experimental runs at all sites (Fig. 1). At $y=0 \mathrm{~m}$ (i.e. directly downstream), mean rate averaged across all sites ranged from $74 \%$ at $x=1 \mathrm{~m}$ through $34 \%$ at $x=16 \mathrm{~m}$ to $31 \%$ at $x=32 \mathrm{~m}$.
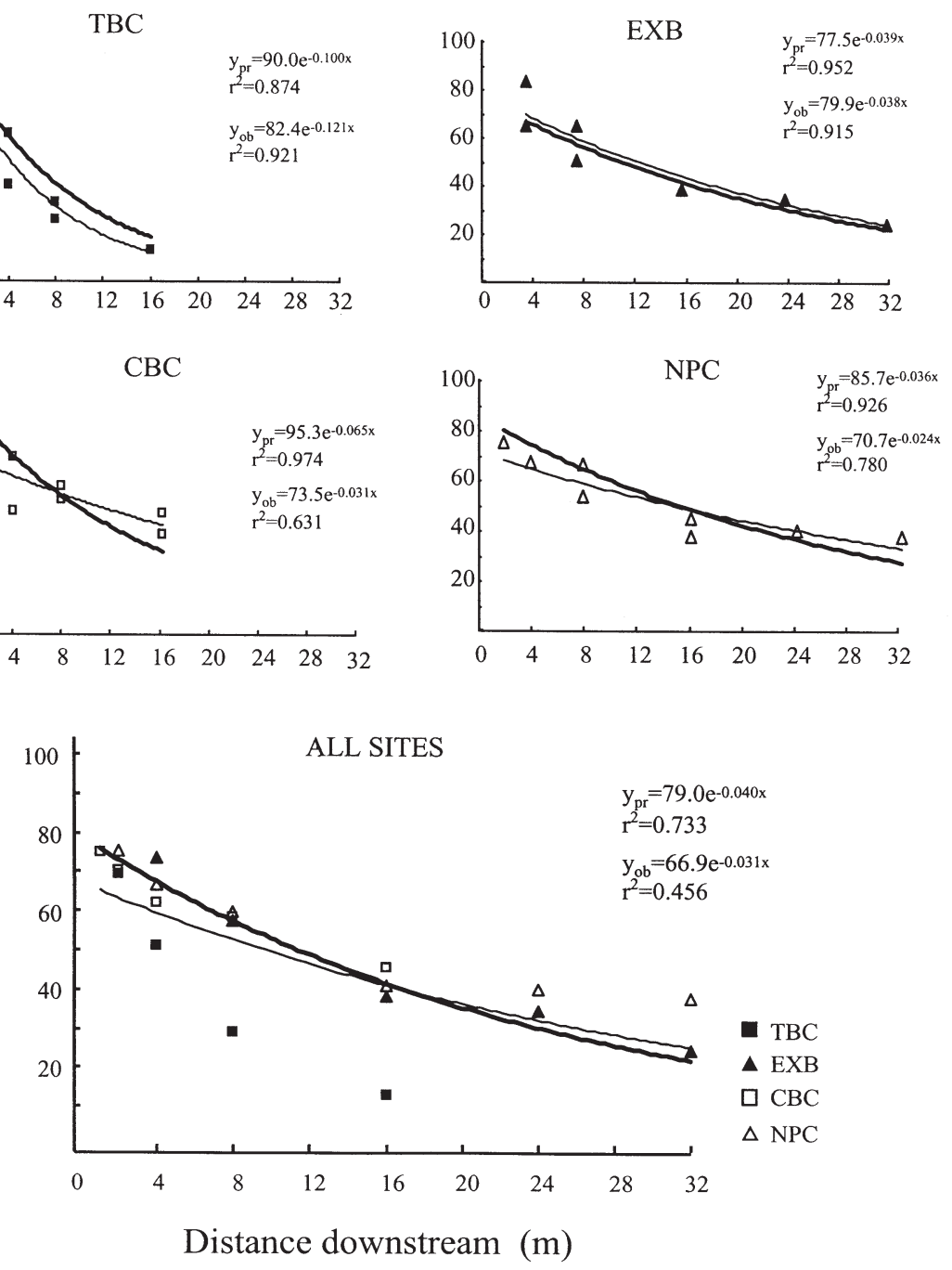

Fig. 1. Oreaster reticulatus. Rates of fertilization observed in field experiments conducted on sand bottoms (TBC, EXB) and in seagrass beds (CBC, NPC) near Lee Stocking Island, Bahamas in August and September 1997, and predicted using the models of gamete diffusion and fertilization kinetics. Data points for each site are observed values for each of 2 runs per site at several distances downstream from a spawning male. Data points for all sites combined are averages of the 2 runs for each site. Equations correspond to exponential curves that were fitted to the observed (light line) and predicted (heavy line) values. Site abbreviations as in legend to Table 1 


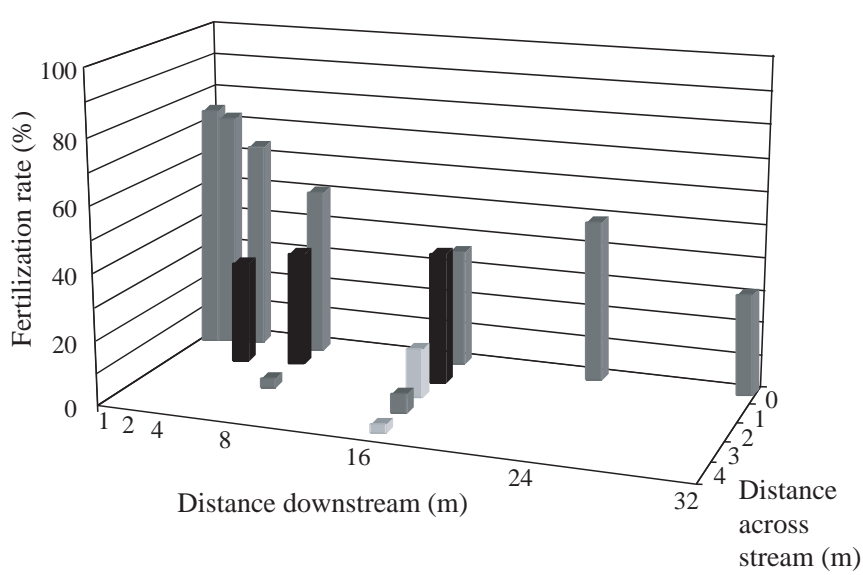

Fig. 2. Oreaster reticulatus. Observed rates of fertilization in field experiments averaged over 4 sites near Lee Stocking Island, Bahamas

Based on rates of fertilization at $y>0 \mathrm{~m}$, the sperm plume was $>2 \mathrm{~m}$ wide at $4 \mathrm{~m}$ downstream and $\sim 8 \mathrm{~m}$ wide at $16 \mathrm{~m}$ downstream. At $\mathrm{x}=4 \mathrm{~m}$ and $y=1 \mathrm{~m}$, mean rate of fertilization was $31.2 \%$, and at $x=16 \mathrm{~m}$ and $y=4 \mathrm{~m}$ it was $0.8 \%$ (Fig. 2). The average rate of fertilization in the control samples collected upstream of the spawning male was $<0.5 \%$, except once when it was $1.5 \%$.

The relationship between rate of fertilization and downstream distance was similar among sites, except at TBC, where the decrease in fertilization with distance was more pronounced than at the other sites. The slope of the curve for TBC was significantly steeper than for the other 3 sites (vs EXB: $t=9.31, \mathrm{p}<$ 0.001, df $=10$; vs CBC: $t=8.84, \mathrm{p}<0.001$, df $=13$; vs NPC: $t=10.91, \mathrm{p}<0.001, \mathrm{df}=11$ ). There was no difference in slopes between the 2 seagrass sites $(t=1.21$, $p>0.2, d f=14$ ), and although the slope of the curve for EXB was steeper than that of NPC $(t=3.20, \mathrm{p}<0.01$, $\mathrm{df}=11$ ), the difference was very small. We found no significant difference between elevations of the curves for any paired comparison of sites.

Curve fitting to the flow profiles indicated that they occurred within a logarithmic boundary layer during all experimental runs (Fig. 3). Free-stream velocity during the experiments ranged from 0.20 to $0.44 \mathrm{~m} \mathrm{~s}^{-1}$ on sand bottoms and from 0.16 to $0.39 \mathrm{~m} \mathrm{~s}^{-1}$ in seagrass beds.

\section{Dye diffusion experiments}

The concentration of dye decreased and the vertical and horizontal expansions of the plumes increased as power functions of the distance downstream from the point of release (Figs $4 \& 5$ ). The width and height of the plume were similar at $\mathrm{TBC}$ and $\mathrm{CBC}$, but were smaller at PPT, which is the shallower site. On average, plume width increased from $0.5 \mathrm{~m}$ at $x=0.5 \mathrm{~m}$ to $2 \mathrm{~m}$ at $x=4 \mathrm{~m}$, and plume height increased from $0.2 \mathrm{~m}$ at $x=$ $0.5 \mathrm{~m}$ to $1.2 \mathrm{~m}$ at $x=4 \mathrm{~m}$ (Fig. 5). Accordingly, $\sigma_{y}$ ranged from 0.058 to 0.175 at $x=0.5 \mathrm{~m}$, and from 0.413 to 0.625 at $x=4 \mathrm{~m}$; and $\sigma_{z}$ ranged from 0.046 to 0.104 at $x=0.5 \mathrm{~m}$, and from 0.208 to 0.417 at $x=4 \mathrm{~m}$.

As with the field fertilization experiments, curve fitting to the flow profiles indicated consistently that we were sampling a logarithmic boundary layer (Fig. 6). Free-stream velocity during the dye diffusion measurements ranged from 0.09 to $0.40 \mathrm{~m} \mathrm{~s}^{-1}$ on sand bottoms, and from 0.11 to $0.30 \mathrm{~m} \mathrm{~s}^{-1}$ in seagrass beds.

\section{Evaluation of the models using field parameterization}

As with the observed values, the rates of fertilization predicted with Eqs (2) \& (3), also decreased exponentially with increasing distance downstream from a spawning male at $y=0 \mathrm{~m}$ (Fig. 1). The shape of the fitted exponentially-decaying curves was similar between the observed and predicted data for sites on sand bottoms, but not in seagrass beds. There was no significant difference in the slopes or elevations between the observed and predicted curves for TBC (slopes: $t=1.62, \mathrm{p}>0.100, \mathrm{df}=10$; elevations: $t=0.14$, $\mathrm{p}>0.500, \mathrm{df}=11$ ) or EXB (slopes: $t=0.34, \mathrm{p}>0.500$, $\mathrm{df}=10$; elevations: $t=0.03, \mathrm{p}>0.500, \mathrm{df}=11$ ) (Fig. 1). For CBC and NPC, the slopes of the predicted curves were significantly steeper than those of the observed curves (CBC: $t=5.59, \mathrm{p}<0.001$, df $=16$; NPC: $t=$ $3.11, \mathrm{p}<0.005, \mathrm{df}=12$ ), but there was no difference in elevations (CBC: $t=0.03, \mathrm{p}>0.500, \mathrm{df}=17$; NPC: $t=$ $0.02, \mathrm{p}>0.500, \mathrm{df}=13$ ) (Fig. 1). When the data from all sites were pooled, no significant differences in the slopes or elevations between the observed and predicted curves were retained (slopes: $t=1.54, \mathrm{p}>$ $0.100, \mathrm{df}=36$; elevations: $t=0.06, \mathrm{p}>0.500, \mathrm{df}=37$ ) (Fig. 1). There was a highly significant correlation between the observed and predicted data at each distance downstream for each run, at $y=0 \mathrm{~m}$ (Fig. 7). However, the performance of the model for $y>0 \mathrm{~m}$ was consistently poor, and in all cases the predicted values were 1 to 10 orders of magnitude lower than the observed ones.

Also in agreement with the observed values, the predicted concentrations of dye decreased as a power function of distance downstream from the point of release (Fig. 4). We generated 2 sets of predicted values that differed in the method of quantification of turbulent diffusivity: for one set, we used calculated values of $\alpha_{y}$ and $\alpha_{z}$ and for the other, we used measured values of $\sigma_{Y}$ and $\sigma_{z}$. The performance of the dif- 

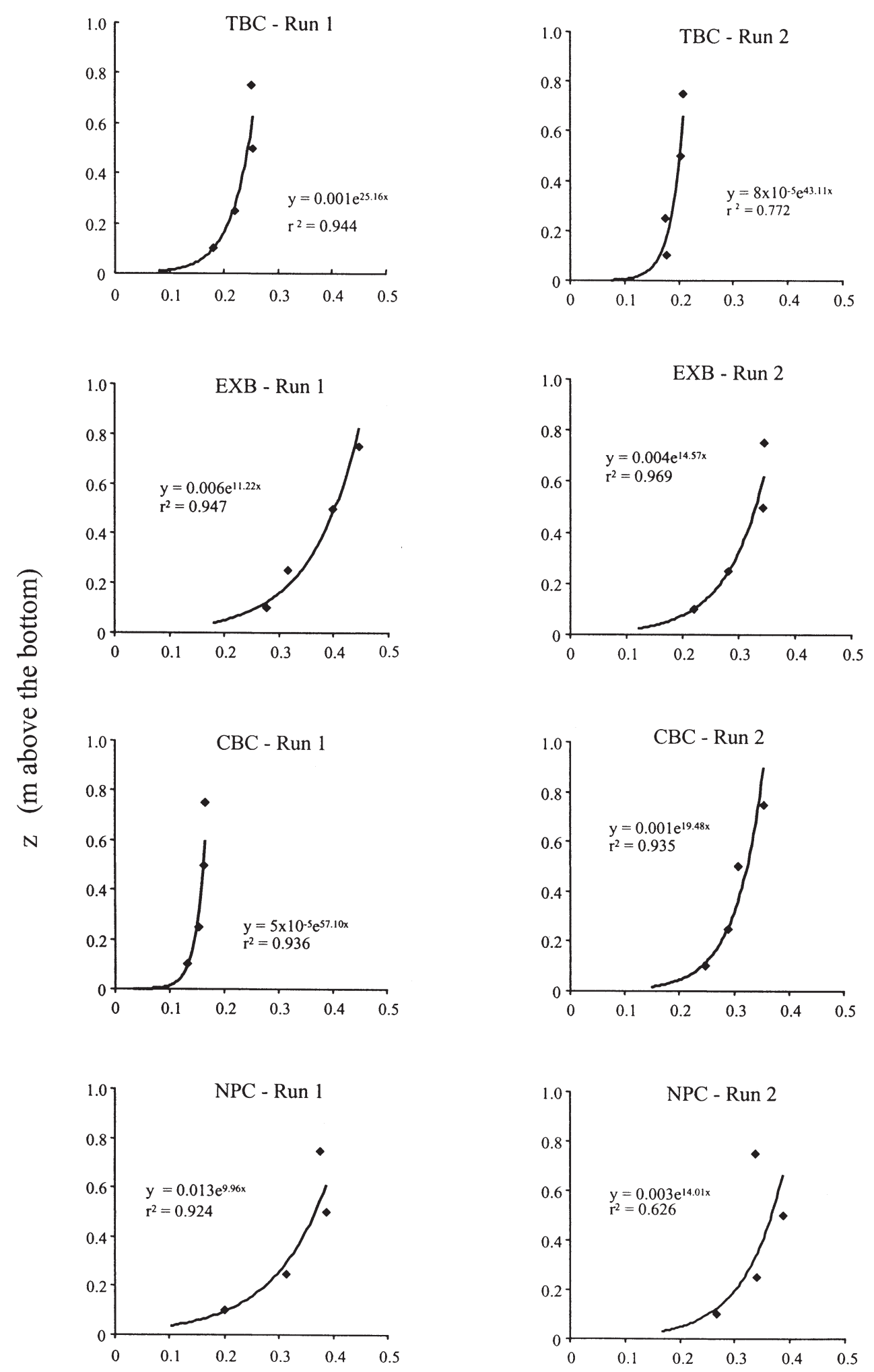

$$
u\left(\mathrm{~m} \mathrm{~s}^{-1}\right)
$$

Fig. 3. Flow profiles $(u=$ free-stream velocity) measured immediately before the individual field experiments of in situ fertilization. Site abbreviations as in legend to Table 1 


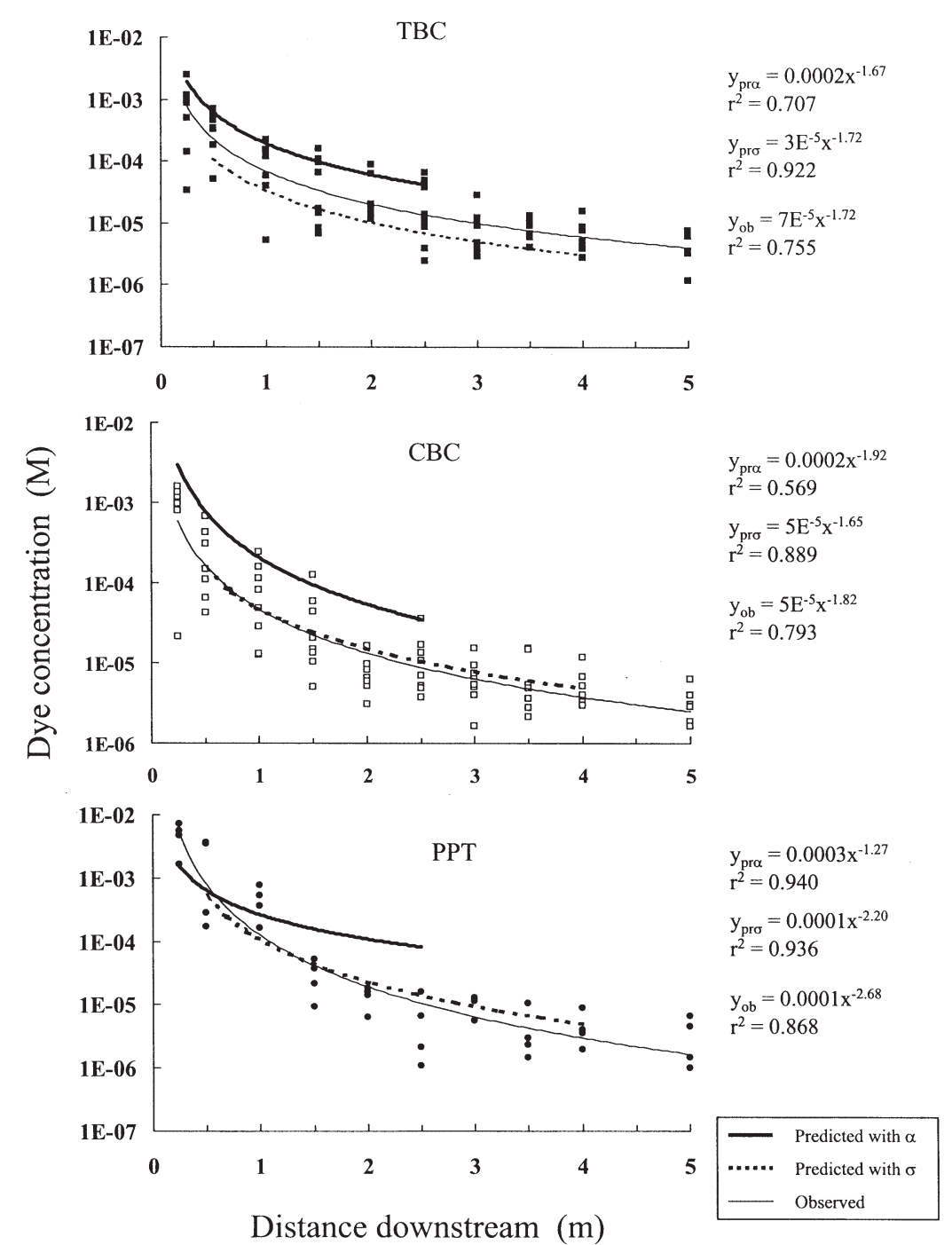

Fig. 4. Observed and predicted concentration of dye in experimental dye releases conducted on sand bottoms (TBC, PPT) and in seagrass beds (CBC) near Lee Stocking Island, Bahamas. Data points are observed values for individual runs per site at several distances downstream from the position of dye release. Equations correspond to power curves fitted to observed values and to values predicted using $\alpha$ and $\sigma$ as measures of turbulent diffusivity. PPT: Pudding Point; other site abbreviations as in legend to Table 1 fusion model was superior using the latter method of quantification. Using $\alpha_{y}$ and $\alpha_{z}$, there was no significant difference in the slopes or elevations between the observed and predicted curves for TBC (slopes: $t=$ 1.50, p > 0.100, df $=172$; elevations: $t$ $=0.58, \mathrm{p}>0.500, \mathrm{df}=173$ ) or $\mathrm{CBC}$ (slopes: $t=0.46, \mathrm{p}>0.500, \mathrm{df}=124$; elevations: $t=0.23, \mathrm{p}>0.500, \mathrm{df}=$ 125) (Fig. 4). For the shallow site (PPT), the slope of the observed curve was significantly steeper than the predicted slope $(t=6.01, \mathrm{p}<$ 0.001 , df $=60$ ), but there was no difference in elevations between the two $(t=0.33, \mathrm{p}>0.500, \mathrm{df}=61)$. There was a highly significant correlation between the observed and predicted data for $x<3 \mathrm{~m}$ (when $z=$ 0.1 or $0.2 \mathrm{~m}$ ), but at greater distances (when $z=0.5 \mathrm{~m}$ ), the predicted values were up to 24 orders of magnitude lower than the observed values, and thus excluded from curve-fitting and correlation analyses (Fig. 8). Using $\sigma_{y}$ and $\sigma_{z}$ allowed us to include all downstream distances in the analyses. We found no significant difference in the slopes (TBC: $t$ $=0.86, \mathrm{p}>0.500, \mathrm{df}=129 ; \mathrm{CBC}: t=$ $0.64, \mathrm{p}>0.500, \mathrm{df}=91$; PPT: $t=0.36$, $\mathrm{p}>0.500, \mathrm{df}=46$ ) or elevations (TBC: $t=0.70, \mathrm{p}>0.500, \mathrm{df}=130$; CBC: $t=0.18, \mathrm{p}>0.500, \mathrm{df}=92$; PPT: $t=0.03, \mathrm{p}>0.500, \mathrm{df}=47$ ) between the observed and predicted curves for any site (Fig. 4), and a highly significant correlation between the observed and predicted data (Fig. 8).
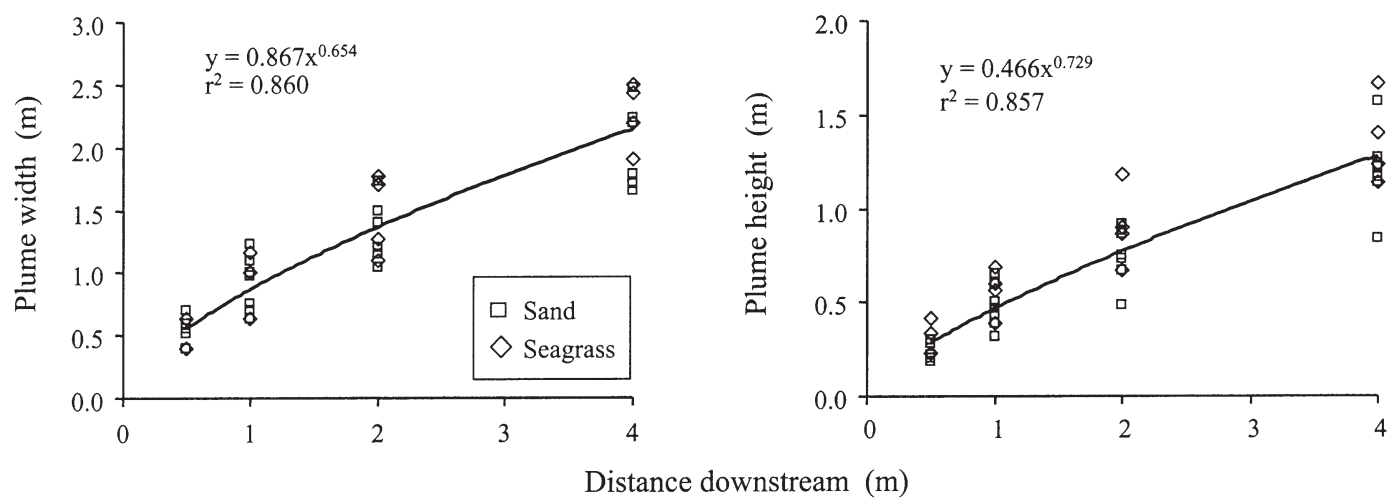

Fig. 5. Vertical and horizontal expansion of plumes of dye measured at 1 site on sand bottom (TBC) and 1 in a seagrass bed (CBC) in June 1996. Data are replicate measures at each distance downstream for separate

Distance downstream (m) releases 


\section{DISCUSSION}

\section{Evaluation of the models}

We assessed the ability of the models of gamete diffusion and fertilization kinetics to predict fertilization success in Oreaster reticulatus by comparing predicted values with empirical measures from the field. For most comparisons, we used frictional velocity to calculate $\alpha_{y}$ and $\alpha_{z}$ as an estimate of turbulent diffusivity. Our values for $\alpha_{z}$ were much lower than those in previous studies (e.g. Babcock et al. 1994, 2000, Levitan \& Young 1995; but see Young et al. 1992), indicating lower rates of turbulent diffusion. Generally, the models predicted accurately both fertilization rate and dye concentration directly downstream from the point of sperm and dye release, respectively, along the main axis of current flow and relatively near bottom (i.e. well within the benthic boundary layer). However, the models did not perform satisfactorily for $y>0$, and $z>0.2 \mathrm{~m}$. This inadequacy was alleviated (at least along the vertical axis) when we quantified
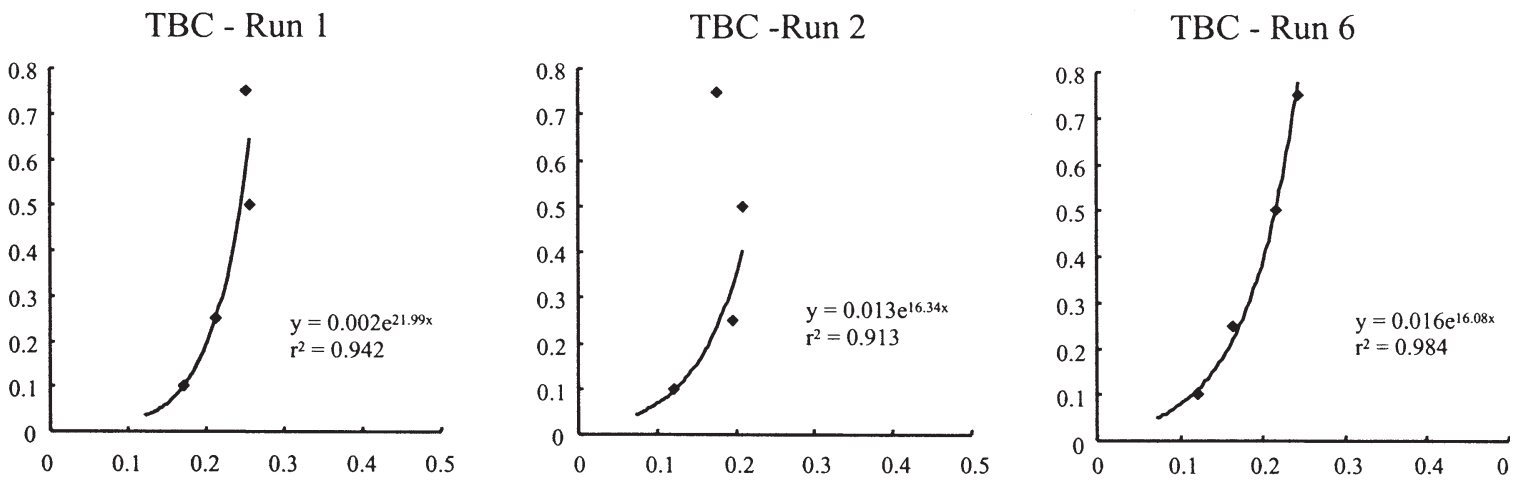

CBC - Run 2

\section{CBC - Run 4}
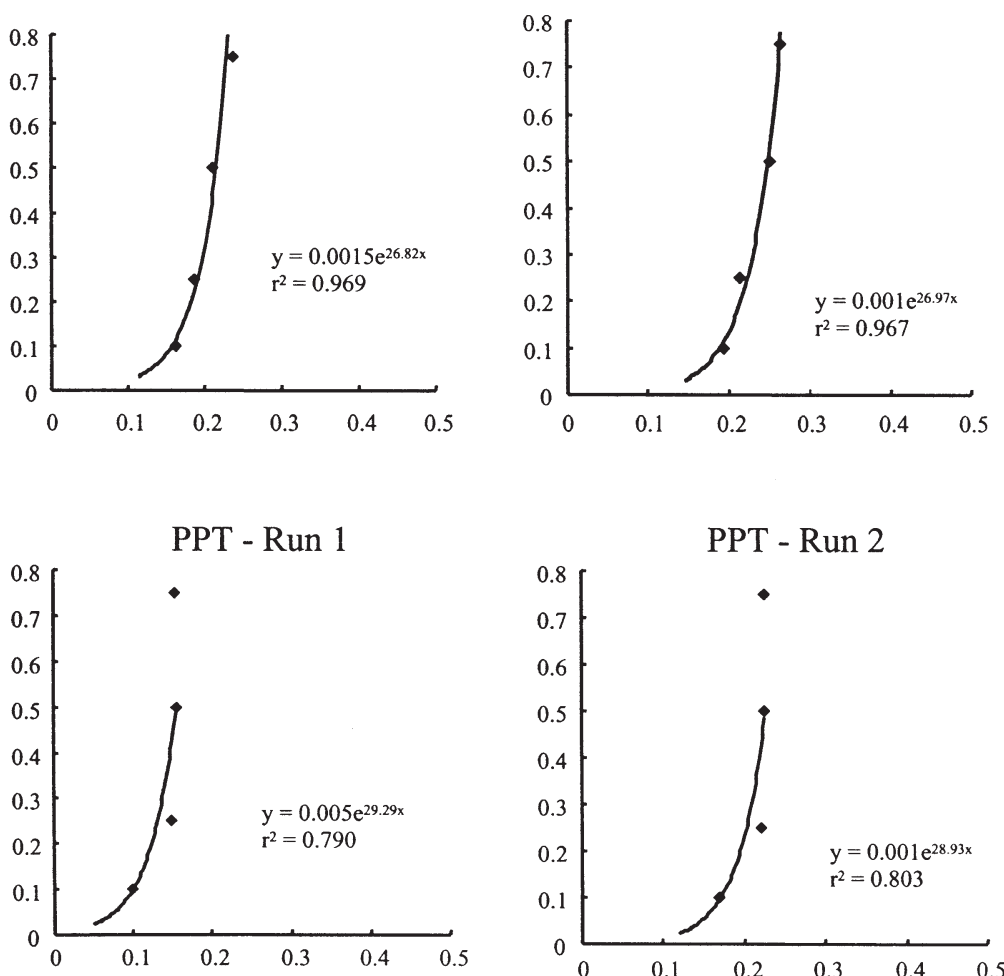

PPT - Run 2

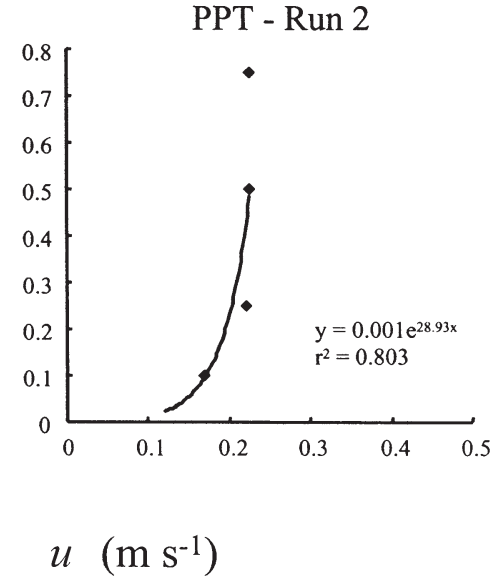

\section{CBC - Run 5}

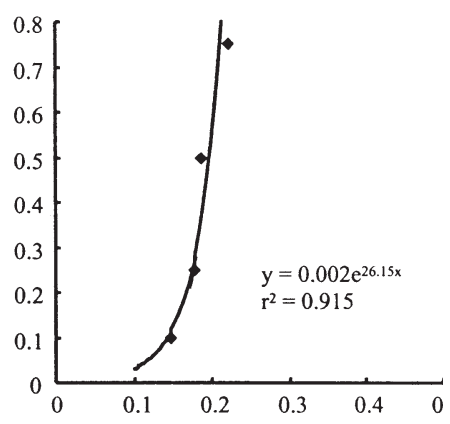

Fig. 6. Selected flow profiles measured immediately before the field experiments of dye. PPT: Pudding Point; other site abbreviations as in legend to Table 1 


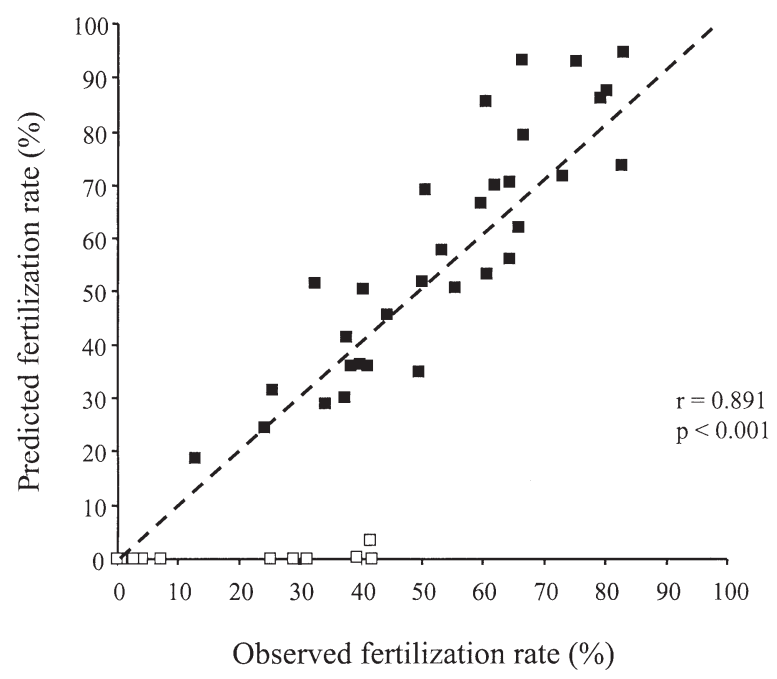

Fig. 7. Relationship between rates of fertilization observed in field experiments and predicted using Eqs (2) \& (3). (-) rates for $y=0$; () rates for $y>0$. Correlation analysis was done only on rates for which $y=0$. Dashed line shows 1:1 relationship turbulent diffusivity with measured values of $\sigma_{y}$ and $\sigma_{z \prime}$ suggesting that, despite their crude measurement, they provided a more accurate description of the dye plume than an extrapolation based on $u_{*}$. One possible explanation is that estimating $\alpha_{y}$ by multiplying $\alpha_{z}$ with a constant (recommended and used in several other studies, e.g. Denny \& Shibata 1989, Young et al. 1992) may not be applicable to all systems, particularly shallow ones. Alternatively, the assumption of the diffusion model that the distribution of the concentration of particles within the plume does not change with time or distance may be incorrect. A direct measure of the shape of the plume circumvents this assumption.

Quantification of turbulent diffusivity remains a challenge in fluid mechanics, and it has been largely ignored in fertilization ecology. Studies that have used the diffusion model have involved empirical measurements to different degrees. One approach has been to parameterize the diffusion equation using literaturebased values for $\alpha_{y}$ and $\alpha_{z}$ (e.g. Denny 1988, Denny \& Shibata 1989), which were derived for atmospheric dif-

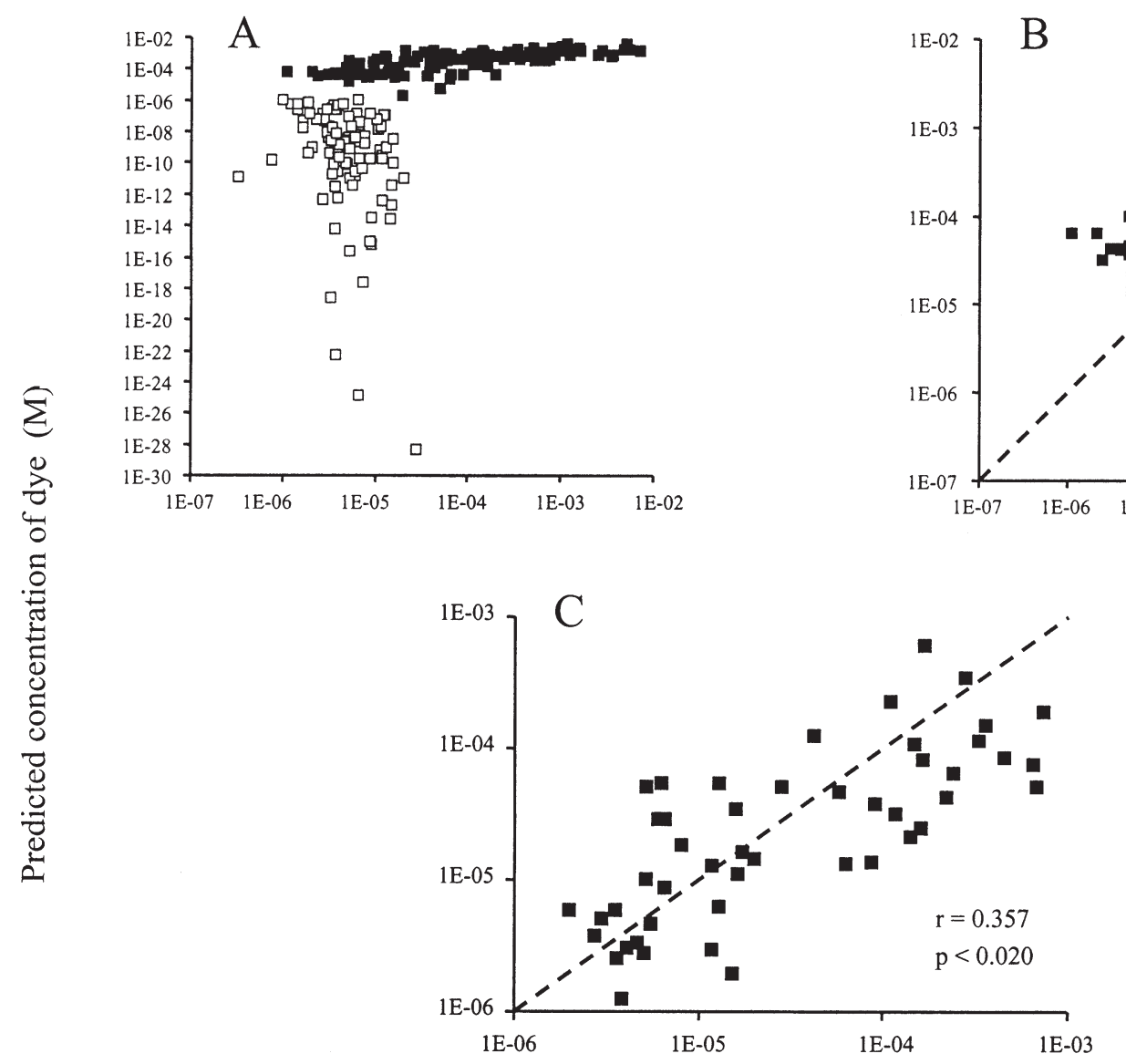

Observed concentration of dye (M)
Fig. 8. Relationship between concentrations of the dye observed in experiments of dye diffusion and predicted using 2 different measures of turbulent diffusivity. In (A) and (B), $\alpha_{y}$ and $\alpha_{z}$ were used to quantify turbulent diffusivity; ( $\mathbf{\square})$ rates for $z<0.5$; $(\square)$ rates for $z=0.5$. Correlation analysis in (B) was done only on rates for which $z<0.5$. In $(C), \sigma_{y}$ and $\sigma_{z}$ were used to quantify turbulent diffusivity. All data were included in the corelation analysis. Dashed lines show 1:1 relationships 
fusion. Alternatively, Eq. (6) has been parameterized using a combination of literature-based values for $\alpha_{y_{1}}$ $\alpha_{z}$ and $\beta$, with $u_{*}$ estimated from empirical flow speeds with Eq. (1) (e.g. Levitan \& Young 1995, Babcock \& Keesing 1999). The most quantitative approach has been the one we used to parameterize $\alpha_{y}$ and $\alpha_{z}$ in Eq. (2), which only involves the assumption of the multiplicative relationship between $\alpha_{y}$ and $\alpha_{z}$ (e.g. Young et al. 1992). A recent study used dye dilutions to quantify $\alpha_{y}$ and $\alpha_{z}$, which were then used to calculate $6 y$ and $6 z$ in Eq. (6), but the method of measurement of these values was unclear (Babcock et al. 2000). Babcock et al. (1994) obtained values for $\sigma_{y_{1}} \sigma_{z}$ and $\beta$ by fitting the models to a subset of empirical rates of fertilization. Our study is the first to obtain independent measures of $u_{*}$ (and thus $\alpha_{y}$ and $\alpha_{z}$ ), and $\sigma_{y}$ and $\sigma_{z}$ concurrently and for individual experimental runs, allowing us to examine directly the validity of the model of gamete diffusion.

The models were less accurate in predicting fertilization success in seagrass beds than on sand bottoms. The steeper slope of the predicted than the observed curves implies that the model overestimated rate of fertilization at near distances and underestimated it farther downstream. There is a pronounced influence of the presence of a canopy of seagrass on the benthic boundary layer, and the assumption of a logarithmic flow profile may not hold in these habitats for near-bed distances $<15 \mathrm{~cm}$ (scale of blade length and height of egg release). Flow speed and turbulent kinetic energy can be an order of magnitude lower within than above the canopy, increasing the probability of deposition of particles within the bed (Ackerman 1986, Eckman 1987, Koch \& Gust 1999). Because of an increase in mechanical turbulence, small eddies are generated by the shoots and subsequently shed, and flow can become oscillatory through the action of waving leaves (Ackerman \& Okubo 1993). Free-stream flow is retarded and $u_{*}$ can be enhanced by an order of magnitude both above the canopy and with increasing distance into the seagrass bed (Gambi et al. 1990). Additionally, advection and diffusion downstream are reduced by the presence of a seagrass bed (Worcester 1995). The shallow slope of observed fertilization success implies a greater retention of sperm than predicted by the coefficients of diffusivity in the model. This may be because assumptions in the calculation of either $u_{*}$ directly, or $\alpha_{y}$ and $\alpha_{z}$ are invalid for seagrass beds. Alternatively, the lack of difference between the observed and predicted curves of dye dilution suggests that the inaccurate estimate of rate of fertilization may have arisen in the model of fertilization kinetics, but only if sperm behaves as a passive tracer like dye. It may be inappropriate to substitute swimming speed of sperm with $u_{*}$ for the reduced flow within the seagrass canopy.

\section{Fertilization success of Oreaster reticulatus}

The rates of fertilization that we measured in the field experiments for Oreaster reticulatus were similar to those measured in other sea stars, such as Acanthaster planci (Babcock et al. 1994) and Coscinasterias muricata (Babcock et al. 2000), and the abalone Haliotis laevigata (Babcock \& Keesing 1999), but were much higher than in echinoids, such as Strongylocentrotus droebachiensis (Pennington 1985), the tropical Diadema antillarum (Levitan 1991), and the bathyal Stylocidaris lineata (Young et al. 1992). We recorded rates as high as $20 \%$ at $32 \mathrm{~m}$ downstream, suggesting that the low population density of $O$. reticulatus may not be as prohibitive as we suspected to successful fertilization and zygote production. Because $O$. reticulatus feeds on sediments with low organic content, individuals must sample large areas to obtain sufficient resources (Scheibling 1980, 1982a). The spatial distribution of a population of this sea star probably reflects a trade-off between a density that minimizes competition during feeding and one that maximizes the probability of fertilization (Scheibling 2001).

Fertilization rate varied little among sites, except for the low values observed at TBC. Because of the agreement between observed and predicted values, and since only characters of the flow profile varied among sites in the parameterization of the model, this pattern probably resulted from differences in hydrodynamics. The frictional velocity $\left(u_{*}\right)$ during the second experimental run at TBC was the lowest of all trials at all sites, although free-stream velocity did not show a similar pattern. The resulting increased coefficients of vertical (and consequently horizontal) turbulent diffusivity imply a greater dilution of sperm, and thus lower rates of fertilization downstream of the point of release.

The relationship between experimental and natural rates of fertilization is unclear. Because spawning events in echinoderms are unpredictable, records of natural rates have been opportunistic (e.g. Minchin 1987, 1992, Babcock et al. 1992, Gladstone 1992). Although fertilization success during natural spawning events can be quite high (Acanthaster planci: 83\%, Babcock \& Mundy 1992; Cucumaria miniata: 86 to 99\%, Sewell \& Levitan 1992; C. frondosa: 60 to 85\%, Hamel \& Mercier 1996), the high experimental rates are generally viewed with great caution, mainly because of potential effects of procedural artifacts.

One procedural aspect of unknown consequence is the artificial induction of spawning by injection of chemicals such as 1-methyladenine or KCL. In our experiments, $67 \%$ of the sea stars both in the field and the laboratory spawned upon injection, and period and intensity of spawning varied greatly among individuals. To account for this variability, we used 32 individu- 
als from different populations and years to obtain the average rate of gamete release used in Eq. (2). Another discrepancy may arise if the sea stars naturally undergo only a single spawning event each season. We dissected 2 individuals, previously induced to spawn in the laboratory, and their gonad index was similar to that of individuals that were not injected, suggesting that a single spawning of the entire gonad did not occur. The wide range in gonad indices and reproductive states of individuals collected from our field sites at the time of the experiments (unpubl. data) suggests that sea stars in the field also undergo more than 1 spawning event.

The use of realistic sperm-egg contact times in field experiments is one of the main limitations in generating accurate measures of natural rates of fertilization. The contact time is determined by the method of collection of eggs, which has been criticised in previous studies. In studies that used syringes or pumps (e.g. Pennington 1985, Babcock \& Mundy 1992, Babcock et al. 1994), the sperm-egg contact time was inflated by the time after collection when the eggs and sperm remained in the syringe or hose, and fertilization presumably continued to occur. In studies that used baskets of Nitex mesh to hold eggs in position (e.g. Levitan et al. 1992, Levitan 1991, Levitan \& Young 1995), the eggs were exposed to enhanced concentrations of sperm because egg dispersal was inhibited. A similar argument could be made for our experimental proto$\mathrm{col}$, since eggs that were collected in the cod end of the net were being exposed to concentrations of sperm at the point of egg release for an artificially prolonged time period.

Because of the excellent performance of the models in predicting rate of fertilization at $y=0 \mathrm{~m}$, we examined the effect of sperm-egg contact time $(\tau)$ on fertilization success by running the models at $\tau=1$ and $10 \mathrm{~s}$ for each experimental run. There was a pronounced decrease on rate of fertilization with decreasing $\tau$ (Fig. 9). For example, for a decrease in $\tau$ from 30 to $1 \mathrm{~s}$, the rate of fertilization decreased from 94 to $8.9 \%$ at $x=1 \mathrm{~m}$, and from 43.3 to $1.05 \%$ at $x=32 \mathrm{~m}$. Assuming a contact time between 1 and $10 \mathrm{~s}$, rate of fertilization ranges from $8.9-60 \%$ at $x=1 \mathrm{~m}$ to $1.05-10.05 \%$ at $x=32 \mathrm{~m}$.

A factor that will enhance fertilization success in the field, and override an effect of sperm-egg contact time, is synchrony in spawning. Although we have not witnessed natural spawning events for Oreaster reticulatus, all observations in other asteroids involved several individuals (Minchin 1987, 1992, Babcock et al. 1992, Gladstone 1992). Records of 'white froth', 'clouds' and 'slicks' (Minchin 1987, Sewell \& Levitan 1992, Lamare \& Stewart 1998) suggest that great concentrations of gametes are released into the water column during a natural spawning event. Elevated concentrations

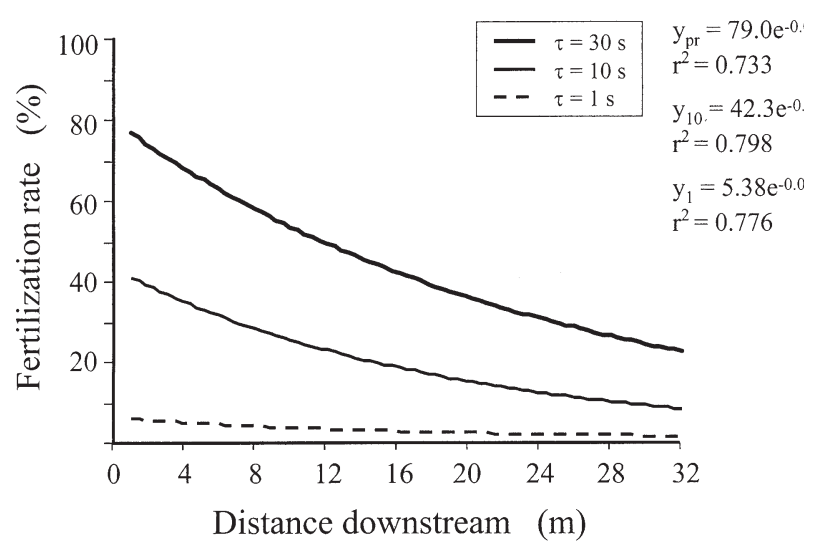

Fig. 9. Oreaster reticulatus. Rates of fertilization (averaged over the 4 sites TBC, EXB, CBC and NPC) predicted with the models of gamete diffusion and fertilization kinetics that were parameterized with flow conditions during experiments of in situ fertilization. Exponential curves were fitted to each of 4 sets of predictions that corresponded to 4 different times of sperm-egg contact. Curve for $\tau=30 \mathrm{~s}$ is the predicted curve averaged for all sites in Fig. 1

of sperm could render the effect of sperm dilution insignificant.

In the areas of adult populations, local hydrodynamics show little net water displacement, with a gradual drift to the north-northwest (i.e. within the Bank) resulting from wind-forcing during the larval period of Oreaster reticulatus (Pitts \& Smith 1994). Thus, larvae are most probably retained within the area of Grand Bahama Bank and concentrated along the north/northwestern side. For queen conch, the main larval source to the Exuma Bank was by tidal transport from adult populations on the Exuma Sound (Stoner \& Davis 1997). Because no such proximate source exists for $O$. reticulatus, and because it is unlikely that larvae are imported from elsewhere in the Caribbean, larval supply is probably localized. Thus, any reduction in the local population density will result in a concomitant decrease in the distribution of potential mates and a devastating effect in the production of zygotes and potential recruits.

Oreaster reticulatus has several life history characteristics that make it particularly vulnerable to extinction because of a slow rate of population recovery. These include slow growth, large size, late onset of reproductive maturity, low recruitment rate, low mortality rate, and long life span (Scheibling 1982b). With increased exploitation, population size may be reduced below a critical threshold required for successful production of zygotes and recruitment, and this species may become locally or even globally extinct. To avoid potentially threatening reductions in the abundance of fragile species such as $O$. reticulatus, we must 
be able to relate changes in the spatial structure of populations to fertilization potential and zygote production. The logistical constraints associated with experiments of in situ fertilization make the use of predictive models quite appealing. We have shown that the 2 models currently used can predict fertilization success reliably for a particular parameter space. Modifications on more accurate descriptions of turbulent diffusion can increase this parameter space, and thus the predictive capacity of the models.

Acknowledgements. We thank Liz Cowie, Tracy Griffin, Brian Kakuk, Manuel Maldonado, Dan McCarthy, Ray Mojica, Mark Robinson, Mary Sewell, and particularly Elsa Vázquez, for their help in the field fertilization experiments. Tracy Griffin and Dan McCarthy did the sectioning and image analysis for the reproductive state of the gonads. Facilities during the experiments were provided by the Caribbean Marine Research Center at Lee Stocking Island, Bahamas. This research was funded by the National Undersea Research Program (USA), the Natural Sciences and Engineering Research Council (Canada) and the National Science Foundation (USA). This is HBOI contribution no. 1415.

\section{LITERATURE CITED}

Ackerman JD (1986) Mechanistic implications for pollination in the marine angiosperm Zostera marina. Aquat Bot 24: 343-353

Ackerman JD, Okubo A (1993) Reduced mixing in a marine macrophyte canopy. Funct Ecol 7:305-309

Babcock R, Keesing J (1999) Fertilization biology of the abalone Haliotis laevigata: laboratory and field studies. Can J Fish Aquat Sci 56:1668-1678

Babcock RC, Mundy CN (1992) Reproductive biology, spawning and field fertilization rates of Acanthaster planci. Aust J Mar Freshwater Res 43:525-534

Babcock R, Mundy C, Keesing J, Oliver J (1992) Predictable and unpredictable spawning events: in situ behavioural data from free-spawning coral reef invertebrates. Invertebr Reprod Dev 22:213-228

Babcock R, Mundy CN, Whitehead D (1994) Sperm diffusion models and in situ confirmation of long-distance fertilization in the free-spawning asteroid Acanthaster planci. Biol Bull 186:17-28

Babcock R, Franke E, Barr N (2000) Does spawning depth affect fertilization rates? Experimental data from the sea star Coscinasterias muricata. Mar Freshw Res 1:55-61

Coma R, Lasker HR (1997a) Effects of spatial distribution and reproductive biology on in situ fertilization rates of a broadcast-spawning invertebrate. Biol Bull 193:20-29

Coma R, Lasker HR (1997b) Small-scale heterogeneity of fertilization success in a broadcast spawning octocoral. J Exp Mar Biol Ecol 214:107-120

Csanady GT (1973) Turbulent diffusion in the environment. Geophysics and astrophysics monographs. D. Reidel Publishing Company, Boston

Denny MW (1988) Biology and the mechanics of the waveswept environment. Princeton University Press, Princeton

Denny MW, Shibata MF (1989) Consequences of surf-zone turbulence for settlement and external fertilization. Am Nat 134:859-889
Eckman JE (1987) The role of hydrodynamics in recruitment growth, and survival of Argopecten irradians (L.) and Anomia simplex (D'Orbigny) within eelgrass meadows. J Exp Mar Biol Ecol 106:165-191

Gambi MC, Nowell ARM, Jumars PA (1990) Flume observations on flow dynamics in Zostera marina (eelgrass) beds. Mar Ecol Prog Ser 61:159-169

Gladstone W (1992) Observations of crown-of-thorns starfish spawning. Aust J Mar Freshw Res 43:535-537

Hamel JF, Mercier A (1996) Gamete dispersion and fertilization success of the sea cucumber Cucumaria frondosa. SPC Beche-de-Mer Inf Bull 8:34-40

Koch EW, Gust G (1999) Water flow in tide- and wave-dominated beds of the seagrass Thalassia testudinum. Mar Ecol Prog Ser 184:63-72

Lamare MD, Stewart BG (1998) Mass spawning by the sea urchin Evechinus chloroticus (Echinodermata: Echinoidea) in a New Zealand fiord. Mar Biol 132:135-140

Lasker HR, Brazeau DA, Calderon J, Coffroth MA, Coma R, Kim K (1996) In situ rates of fertilization among broadcast spawning gorgonian corals. Biol Bull 190:45-55

Levitan DR (1991) Influence of body size and population density on fertilization success and reproductive output in a free-spawning invertebrate. Biol Bull 181:261-268

Levitan DR (1995) The ecology of fertilization in free-spawing invertebrates. In: McEdward L (ed) Ecology of marine invertebrate larvae. CRC Press, Boca Raton, p 123-156

Levitan DR, Young CM (1995) Reproductive success in large populations: empirical measures and theoretical predictions of fertilization in the sea biscuit Clypeaster rosaceus. J Exp Mar Biol Ecol 190:221-241

Levitan DR, Sewell MA, Chia FS (1992) How distribution and abundance influence fertilization success in the sea urchin Strongylocentrotus franciscanus. Ecology 73:248-254

Minchin D (1987) Sea-water temperature and spawning behaviour in the seastar Marthasterias glacialis. Mar Biol 95:139-143

Minchin D (1992) Multiple species, mass spawning events in an Irish sea lough: the effect of temperatures on spawning and recruitment of invertebrates. Invertebr Reprod Dev 22:229-238

Okubo A (1980) Diffusion and ecological problems: mathematical models. Springer-Verlag, New York

Oliver J, Babcock R (1992) Aspects of fertilization ecology of broadcast spawning corals: sperm dilution effects and in situ measurements of fertilization. Biol Bull 183:409-417

Pennington JT (1985) The ecology of fertilization of echinoid eggs: the consequences of sperm dilution, adult aggregation, and synchronous spawning. Biol Bull 169:417-430

Petersen CW (1991) Variation in fertilization rate in the tropical reef fish, Halichoeres bivattatus: correlates and implications. Biol Bull 181:232-237

Petersen CW, Warner RR, Cohen S, Hess HC, Sewell AT (1992) Variable pelagic fertilization success: implications for mate choice and spatial patterns of mating. Ecology 73: 391-401

Pitts PA, Smith NP (1994) Annotated summary of current meter data from the vicinity of Lee Stocking Island, Exuma Cays, Bahamas. Carib Mar Res Center Tech Rep Ser No. $94-4$

Scheibling RE (1980) The microphagous feeding behavior of Oreaster reticulatus (Echinodermata: Asteroidea). Mar Behav Physiol 7:225-232

Scheibling RE (1982a) Feeding habits of Oreaster reticulatus (Echinodermata: Asteroidea). Bull Mar Sci 32:504-510

Scheibling RE (1982b) The annual reproductive cycle of Oreaster reticulatus (L.) (Echinodermata: Asteroidea) and 
interpopulation comparisons of reproductive capacity. J Exp Mar Biol Ecol 54:39-54

Scheibling RE, Metaxas A (2001) Population characteristics of the sea star Oreaster reticulatus in the Bahamas and across the Caribbean. In: Barker MF (ed) Proceedings of the 10th International Echinoderms Conference. AA Balkema, Rotterdam

Scheibling RE (2001) Of size and space: an evolutionary trade-off in fertilization strategy among oreasterid sea stars. In: Barker MF (ed) Proc 10th Int Echinoderms Conf. AA Balkema, Rotterdam

Sewell MA, Levitan DR (1992) Fertilization success during a natural spawning of the dendrochirote sea cucumber Cucumaria miniata. Bull Mar Sci 51:161-166

Stoner AW, Davis M (1997) Abundance and distribution of queen conch veligers (Strombus gigas Linne) in the central Bahamas. I. Horizontal patterns in relation to reproductive and nursery grounds. J Shellfish Res 16:7-18

Styan CA (1998) Polyspermy, egg size, and the fertilization

Editorial responsibility: Roger Hughes (Contributing Editor), Bangor, Wales, UK kinetics of free-spawning marine invertebrates. Am Nat 152:290-297

Vogel H, Chizak G, Chang P, Wolf P (1982) Fertilization kinetics of sea urchin eggs. Math Biosci 58:189-216

Wahle RA, Peckham SH (1999) Density-related reproductive trade-offs in the green sea urchin, Strongylocentrotus droebachiensis. Mar Biol 134:127-137

Worcester SE (1995) Effects of eelgrass beds on advection and turbulent mixing in low current and low shoot density environments. Mar Ecol Prog Ser 126:223-232

Yoshida M (1952) Some observations on the maturation of the sea urchin, Diadema setosum. Annotnes Zool Jap 25: 265-271

Young CM, Tyler PA, Cameron JL, Rumrill SG (1992) Seasonal breeding aggregations in low-density populations of the bathyal echinoid Stylocidaris lineata. Mar Biol 113: 603-612

Zar JH (1999) Biostatistical analysis. 4th edn. Prentice-Hall, Upper Saddle River, NJ

Submitted: October 30, 2000; Accepted: May 8, 2001

Proofs received from author(s): January 15, 2002 